f falsely believed the object was hidden.

The authors suggest an implicit theory of mind predates human evolution. Science 354, 110-114 (2016)

\section{Warmer forests store less carbon}

Climate change might reduce the amount of carbon that forests can store, in part because photosynthesis decreases at high temperatures.

Emily Meineke and her colleagues at North Carolina State University in Raleigh studied willow oaks (Quercus phellos) in the local area, where - as in other large cities - pavement and other hard surfaces absorb and slowly radiate the Sun's heat. This increases the temperature in some urban regions to a level comparable to that predicted for the next century as climate warming continues. The team measured trees' photosynthetic rate, as well as factors such as water stress and pest prevalence, in hotter and cooler areas of Raleigh.

Hotter areas saw less tree growth. The team calculates that the 'urban heat island' effect reduced carbon sequestration in these trees by $12 \%$. The reduction in growth was driven mainly by the effect of water deficits on photosynthesis, not increased herbivore activity.

Proc. R. Soc. B 283, 20161574 (2016)

\section{MARINE BIOLOGY}

\section{Diatoms sink in fits and starts}

Single-celled marine organisms called diatoms can rapidly alter the speed at which they move through the water column, despite lacking structures for motility.

Diatoms are photosynthetic and are a major contributor to ocean productivity. Brad Gemmell and his colleagues at the University of Texas Marine Science Institute in Port

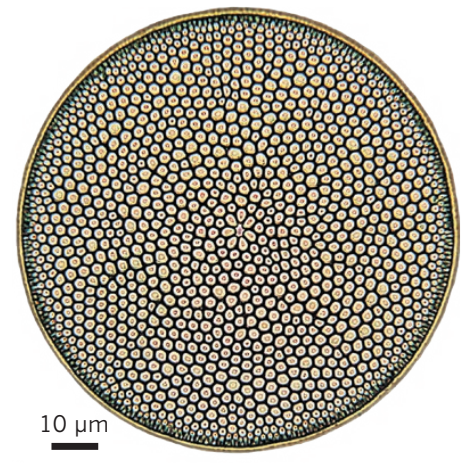

break-up of a planet or comets in the star's system, creating a cloud of spreading debris. Astrophys. J. Lett. in the press; preprint at https://arxiv.org/ abs/1608.01316 (2016)

\section{MICROBIOLOGY}

\section{Gut bacteria help cancer drug}

Certain gut microbes work with a common cancer drug by boosting anti-tumour immune responses, making the therapy more effective in mice.

Laurence Zitvogel of the Gustave Roussy Cancer Campus in Villejuif, France, and his colleagues studied the effect of two species of bacteria on the action of the drug cyclophosphamide. When they gave antibiotic-treated mice the microbe Enterococcus hirae, they found that it made immune cells called T cells more active against specific tumour markers and caused intestinal immune cells to proliferate. Another bacterium, Barnesiella intestinihominis, drove immune cells to infiltrate tumours. In mice that lack a protein that restricts these species' growth, the cancer drug was nearly twice as effective at reducing tumour size than in normal animals.

The results suggest that gut bacteria could be used to optimize cancer therapies, the authors say.

Immunity http://doi.org/brmm (2016)

Benjamin Montet at the California Institute of Technology and Joshua Simon at the Carnegie Observatories, both in Pasadena, used instruments on NASA's Kepler spacecraft to study a star in the constellation Cygnus called KIC 8462852, which is brighter and larger than the Sun. Four years of observations revealed that the star dimmed slowly at first, by around $0.9 \%$ in total, then faded more rapidly by $2 \%$ in only six months. A few other stars nearby also became dimmer, but not to the same extent.

The authors speculate that the star's dimming could be explained by the collision or and his colleagues created such a device with electrodes made only from a nickel-organic framework $\left(\mathrm{Ni}_{3}(\mathrm{HITP})_{2}\right)$ that has high electrical conductivity. The supercapacitor stored more energy per area than most other carbon-based devices, and retained more than $90 \%$ capacity after 10,000 cycles on a par with commercial devices.

Such a supercapacitor could have an important role in future energy grids, the authors say.

Nature Mater. http://dx.doi. org/10.1038/nmat4766 (2016)

\section{PLANETARY SCIENCE \\ Ocean on another of Saturn's moons}

Like its neighbours Titan and Enceladus, Saturn's moon Dione may harbour an ocean beneath its icy surface.

Mikael Beuthe and his colleagues at the Royal Observatory of Belgium in Brussels studied data collected from Enceladus and Dione by NASA's Cassini spacecraft. They looked for small changes in the moons' gravity and shape that can reveal layers of buried liquid. Data modelling suggested that Dione has a 65-kilometre-deep global ocean hidden beneath some 100 kilometres of ice.

Those waters are a possible habitat for extraterrestrial microbes, should they exist. Geophys. Res. Lett. http://doi. org/brg7 (2016)

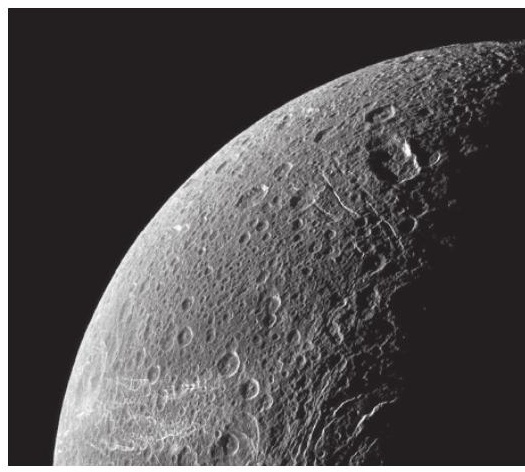

\section{$\rightarrow$ NATURE.COM}

For the latest research published by Naturevisit:

www.nature.com/latestresearch 